\title{
Characterization of Filoplan and Endophytic Mold Isolates Avicennia marina from Mangrove Area, Semarang
}

\author{
Wahyu Aji Mahardhika*, Arina Tri Lunggani, Isworo Rukmi, Dicky Setiawan, \\ Ansalakhul Balayatin Ni'mah, Nur Amalia Firdausa, Dina Devina Anggraeni \\ Departemen Biologi, Fakultas Sains dan Matematika, Universitas Diponegoro, Semarang, Indonesia
}

\author{
Article History \\ Received : June $02^{\text {th }}, 2021$ \\ Revised : July $02^{\text {th }}, 2021$ \\ Accepted : July $16^{\text {th }}, 2021$ \\ Published : July $21^{\text {th }}, 2021$ \\ *Corresponding Author: \\ Wahyu Aji Mahardhika, \\ Universitas Diponegoro, \\ Semarang, Indonesia \\ Email: \\ Mahardhikaaji@gmail.com
}

\begin{abstract}
The presence of fungi in nature is very abundant, but at this time it is still necessary to know and explore the various types that are able to live in various places. Fungi can live in plant tissue, known as endophytic fungi, and can also live on the leaf surface of a plant. Avicennia marina lives on the coast and is used to reduce abrasion, besides being able to live in tidal habitats and high salinity levels. This is supported by the plant's physiology and the help of its microbial symbionts, therefore it is necessary to explore fungi, especially fungi that are able to symbionting with these plants because they are thought to be resistant to high levels of salinity. The purpose of this study was to determine the types of molds that have been isolated and are able to live in the tissue and leaf surface of $A$. marina. Characterization method was reviewed through macroscopic and microscopic morphology using a microscope and compared with literature from various sources. The characterization results of the 12 isolates obtained several genera, including Trichoderma, Aspergillus, Penicillium, Curvularia, Paecilomyces, Talaromyces, Syncephalastrum, and 1 unidentified isolate. These isolates need to be continued with further research to see their ability to produce metabolites and so on.
\end{abstract}

Keywords: Avicennia marina, endophyte, molds, phylloplane

\section{Pendahuluan}

Avicennia marina merupakan tanaman yang umum dijumpai di pantai ataupun di daerah yang mengalami fenomena abrasi. Tanaman tersebut mampu tumbuh dengan baik di lingkungannya jika memiliki salinitas sekitar 0$30 \%$ dan batas toleransinya maksimal hingga $85 \%$ (Robetson \& Alongi, 1992). Peran tersebut tidak lepas dari fisiologis tanaman itu sendiri dan mikroba simbionnya. Mikroba simbion merupakan mikroorganisme yang memiliki hubungan simbiosis mutualisme dengan inangnya (Aroca, 2013). Simbion ini dapat berupa bakteri ataupun fungi. Mikroba simbion salah satunya dapat berupa endofit ataupun filoplan (permukaan daun). Penelitian Wijaya dkk. (2014) membuktikan jika berbagai jamur filoplan ditemukan pada permukaan daun kangkong pada lahan pertanian organic dan konvensional, diantaranya Aspergillus, Geotrichum, Penicillium, Mucor, Fusarium, Cladosporium, Bispora, Blastomyces,
Trichoderma, Botrytis, Curvularia, Nigrospora, Pestalotia, dan Gibberela. Kapang filoplan lain yang ditemukan oleh Shaukat et al. (2014) pada dua spesies mangrove yaitu $C$. tagal dan $A$. corniculatum, diantaranya berasal dari genus Aspergillus, Penicillium, Rhizopus, Alternaria, Gliocladium, Ulocladium, Mucor, dan sebagainya. Baik bakteri maupun fungi tersebut memiliki peranan penting bagi inangnya, seperti penghasil senyawa bioaktif, memiliki peran antagonis terhadap mikroba patogen, membantu dalam pertumbuhan tanaman, dan lain sebagainya (Yan et al., 2019). Mikroba tersebut dapat berperan sebagiai agen yang menguntungkan bagi inang dan ada pula yang merugikan. Yulia (2007) menyatakan jika bakteri filoplan yang diisolasi dari pohon manga memiliki kemampuan antagonis terhadap penyakit antraknosa dan penelitian Lunggani (2018) membuktikan jika aktinomiset yang diisolasi dari Sargassum sp. memiliki kemampuan untuk melarutkan fosfat. Selain bakteri dan aktinomiset, banyak penelitian yang 
mengkaji fungi simbion dari berbagai tanaman dan membuktikan jika mikroba tersebut mampu menghasilkan senyawa yang berguna di berbagai bidang. Penelitian oleh Khaerati (2018) membuktikan bahwa kapang filoplan dan endofit yang diisolasi mampu menjadi biokontrol terhadap fungi patogen. Selain itu penelitian Mahardhika (2021) membuktikan jika kapang endofit yang diisolasi dari ciplukan memiliki potensi penghasil antibakteri. Potensi tersebut tidak lepas terhadap hubungan inang dengan simbionnya. Penelitian Trianto dkk. (2021) membuktikan pula jika fungi yang diisolasi dari berbagai spesies mangrove di Sulawesi Utara memiliki potensi antibakteri, penghasil enzim protease, dan selulase. Sopialena dkk (2019) juga membuktikan bahwa kapang endofitr yang diisolasi dari padi diantaranya memiliki kemampuan untuk membunah serangga atau biasa disebut sebagai kapang entomopatogen. Banyaknya potensi fungi simbion yang telah ditemukan sangat menguntungkan bagi manusia, baik secara diversitas maupun metabolit yang dikeluarkannya. Oleh karena itu, banyak peneliti yang sekarang mulai tertarik pada mikroba simbion pada makhluk hidup. Belum ada penelitian mengenai kapang simbion yang terdapat pada $A$. marina di Pantai Mangkang Semarang. Penelitian ini bertujuan untuk mengetahui karakteristik morfologi beberapa kapang yang berhasil diisolasi dari endofit dan filoplan A. marina di pantai Mangkang, Semarang yang telah diisolasi sebelumnya.

\section{Bahan dan Metode}

\section{Persiapan Alat dan Bahan}

Alat yang digunakan dalam penelitian ini diantaranya mikroskop, hotplate, magnetic stirrer, jarum tanam tajam, gelas objek, kaca penutup, pipet tetes, tabung reaksi, Erlenmeyer, cawan petri. Bahan yang digunakan diantaranya media PDA (Potato Dextrose Agar), mounting fluid (Asam Laktat 3\%), kloramfenikol 50 ppm, dan 12 isolat kapang yang telah diisolasi pada penelitian sebelumnya.

\section{Pembuatan Medium PDA}

Median PDA ready for use sebanyak 39g kemudian dilarutkan dengan akuades $1 \mathrm{~L}$ dan dipanaskan emnggunakan hot plate dan magnetic stirrer. Selanjutnya media PDA disterilisasi menggunakan autoklaf selama 15 menit pada suhu $121^{\circ} \mathrm{C}$ (Atlas, 2010).

\section{Peremajaan Isolat Kapang}

Peremajaan dilakukan dengan memindahkan kultur kapang dari culture stock dan diinokulasikan pada media PDA baru pada cawan petri dan tabung reaksi. Selanjutnya cawan petri dan tabung reaksi yang berisi kultur diinkubasi selama 7 hari pada suhu $25-27^{\circ} \mathrm{C}$. Kultur yang diinokulasikan pada cawan petri akan digunakan untuk karakterisasi morfologi.

\section{Karakterisasi Isolat Kapang}

Kultur kapang yang telah tumbuh kemudian dilakukan karakterisasi morfologi secara makroskopis dan mikroskopis. Karakterisasi morfologi secara makroskopis dilihat dari warna koloni, warna koloni sebaliknya (reverse of colony), tekstur permukaan, ada tidaknya growing zone, tetes eksudat (exudate drops), sclerotia, radial furrow, dan soluble pigment, sedangkan secara mikroskopis dilihat dari ada tidaknya septa pada hifa, warna dan tekstur permukaan hifa, bentuk dan warna konidia, serta struktur lain seperti vesikel, fialid, cleistothecia, sporangium, dan lain sebagainya. Data morfologis yang telah didapat kemudian di cocokan dengan literatur yang ada, antara Food and Indoor Fungi oleh Samsons et al. (2004), Identification of Common Aspergillus Species oleh Klich (2002), Pictorial Atlas of Seed and Soil Fungi oleh Watanabe (2010) dan sebagainya.

\section{Hasil dan Pembahasan}

\section{Karakterisasi Kapang}

Hasil karakterisasi kedua belas kapang secara morfologi makroskopis dan mikroskopis terdapat pada Tabel 1. Berdasarkan hasil karakterisasi pada Tabel 1, sembilan isolat filoplan diketahui berasal dari genus Aspergillus, Curvularia, Trichoderma, Paecilomyces, Penicillium, Syncephalastrum, dan satu jamur yang belum diketahui genusnya. Isolat kapang endofit berdasarkan karakterisasinya diketahui berasal dari genus Talaromyces, dan Penicillium. Menurut penelitian Elkhateeb \& Daba (2018), kapang kapang tersebut seringkali menjadi mikobiota di permukaan daun tanaman, baik tanaman yang 
mengandung nilai ekonomi tinggi maupun di bidang medis. Penelitian Chauhan et al. (2014) membuktikan bahwa beberapa genus kapang seperti Aspergillus, Alternaria, Fusarium, Penicillium, Trichoderma, Cladosporium, Curvularia, Rhizopus, dan beberapa miselia steril dapat ditemukan sebagai mikoflora pada tanaman Dhak.

Kapang dengan kode isolate PFM111 diduga berasal dari genus Aspergillus. Aspergillus merupakan salah satu kapang kosmopolit yang ditemukan di berbagai tempat. Kapang ini mempunyai ciri khas yaitu adanya vesikel pada ujung konidiofor, selain itu memiliki fialid dan juga metula. Kapang PFM111 memiliki koloni berwarna hijau dan masuk ke dalam Section Flavi. Klich (2002) menyatakan jika Aspergillus yang masuk ke dalam section atau grup Flavi memiliki ciri-ciri koloni berwarna hijau hingga hijau kekuningan. Isolat PFM13, EFM3A, dan EFM5B diduga berasal dari genus Penicillium. Penicillium dikenal memiliki kepala konida berbentuk sapu ataupun sikat dan dapat ditemukan di berbagai tempat sehingga merupakan salah satu contoh kapang kosmopolit. Isolat PFM11 dan PFM111 merupakan kapang yang berasal dari genus Trichoderma. Genus ini memiliki ciri-ciri umum koloni berwarna hijau dengan tekstur bertepung, serta secara mikroskopis memiliki hifa yang fialidnya membentuk seperti pohon. Isolat PFM21 merupakan genus Syncephalastrum. Kapang ini memiliki bentuk koloni seperti kapas berwarna putih yang berangsur-angsur menjadi kecoklatan. Morfologi mikroskopis genus ini dikenal memiliki struktur yang dinamakan merosporangium yang didalamnya terdapat merospora, selain itu tidak memiliki septa dan rhizoid. Kapang dengan kode isolat PFM27 dan PFM33 berasal dari genus Curvularia. Kapang ini memiliki ciri khas konida berwarna coklat dan berbentuk seperti ginjal (ren), selain itu memiliki hifa bersekat, dan berpigmen coklat. Isolat PFM4D berasal dari genus Talaromyces. Genus ini diduga merupakan fase seksual dari Penicillium yang ditandai memiliki ascomata (Samsons, et al., 2004). Isolat PFM116 diduga berasal dari genus Paecilomyces. Genus ini memiliki ciri yang mirip dengan Penicillium, akan tetapi fialidnya lebih panjang dan berbentuk seperti botol. 
Tabel 1. Hasil karakterisasi isolate kapang filopan dan endofit tanaman mangrove

\begin{tabular}{|c|c|c|c|c|c|c|c|c|c|c|c|c|c|}
\hline No & & PFM11 & PFM12 & PFM111 & PFM21 & PFM27 & PFM31 & PFM33 & PFM39 & EFM3A & EFM4D & EFM5B & PFM116 \\
\hline \multirow[t]{8}{*}{1} & Koloni : & & & & & & & & & & & & \\
\hline & Warna & Hijau & Kuning & Hijau & Putih & Hitam & Hijau & Coklat & putih & Kuning & Putih,kuning & hijau & $\begin{array}{c}\text { Hijau kusam, } \\
\text { putih }\end{array}$ \\
\hline & Tekstur & Tepung & Beludru & Tepung & Kapas & Beludru & Kapas & Beludru & beludru & Beludur & Beludru & beludru & $\begin{array}{c}\text { Beludru, } \\
\text { sedikit } \\
\text { berkapas }\end{array}$ \\
\hline & Reverse & Hyalin & Kekuningan & Hyalin & Hyalin & Hitam & hyalin & coklat & putih & Putih & Putih & kekuningan & Putih \\
\hline & Soluble Pigment & Kuning & - & - & - & - & - & - & - & - & - & - & - \\
\hline & Radial Furrow & - & - & - & - & - & - & -- & - & -- & - & Ada & - \\
\hline & Exudate Drops & - & - & - & - & - & - & - & - & - & - & - & - \\
\hline & Growing zone & - & - & - & - & - & - & - & - & - & - & - & - \\
\hline \multirow[t]{4}{*}{2} & Hifa & & & & & & & & & & & & \\
\hline & Septa & Ada & Ada & Ada & Tidak & Ada & ada & Ada & ada & Ada & Ada & ada & Ada \\
\hline & Warna & Hyalin & Hyalin & Hyalin & Hyalin & Coklat & hyalin & Coklat & hyalin & Hyalin & Hyalin & hyalin & Hyalin \\
\hline & $\begin{array}{c}\text { Tekstur } \\
\text { permukaan }\end{array}$ & Halus & Halus & Halus & Halus & Halus & halus & Halus & halus & Halus & Halus & halus & Halus \\
\hline \multirow[t]{4}{*}{3} & Konidia & & & & & & & & & & & & \\
\hline & Bentuk & Globose & Subglobose & Globose & - & Reniform & globose & Reniform & $\begin{array}{c}\text { Tdk } \\
\text { ditmukan }\end{array}$ & Globose & Globose & globose & Subglobose \\
\hline & $\begin{array}{c}\text { Tekstur } \\
\text { permukaan }\end{array}$ & Halus & Halus & Halus & - & Halus & halus & Halus & - & Halus & Halus & Halus & Halus \\
\hline & warna & Hijau & Hyalin & Hyalin & - & Coklat & hijau & Coklat & - & Hyalin & Hyalin & Hyalin & Hyalin \\
\hline \multirow[t]{7}{*}{4} & Bagian lain : & & & & & & & & & & & & \\
\hline & Vesikel & - & - & globose & Globose & - & - & - & - & - & - & - & - \\
\hline & Spora & - & - & - & Merospora & - & - & -- & - & -- & - & - & -- \\
\hline & Seriate & - & - & Biseriate & - & - & - & - & - & - & - & - & - \\
\hline & Branch & - & Biverticilate & - & Ada & - & - & - & -- & Biverticiliata & Biverticilata & Biverticilata & Ada \\
\hline & Cleistothecia & - & - & - & - & - & - & - & - & - & Ada & - & - \\
\hline & Chlamydospores & - & - & - & - & - & - & - & ada & - & - & - & - \\
\hline 5 & Perkiraan Genus & Trichoderma & Penicillium & Aspergillus & Syncephalastrum & Curvularia & Trichoderma & Curvularia & $S P 1$ & Penicillium & Talaomyces & Penicillium & Paecilomyces \\
\hline
\end{tabular}



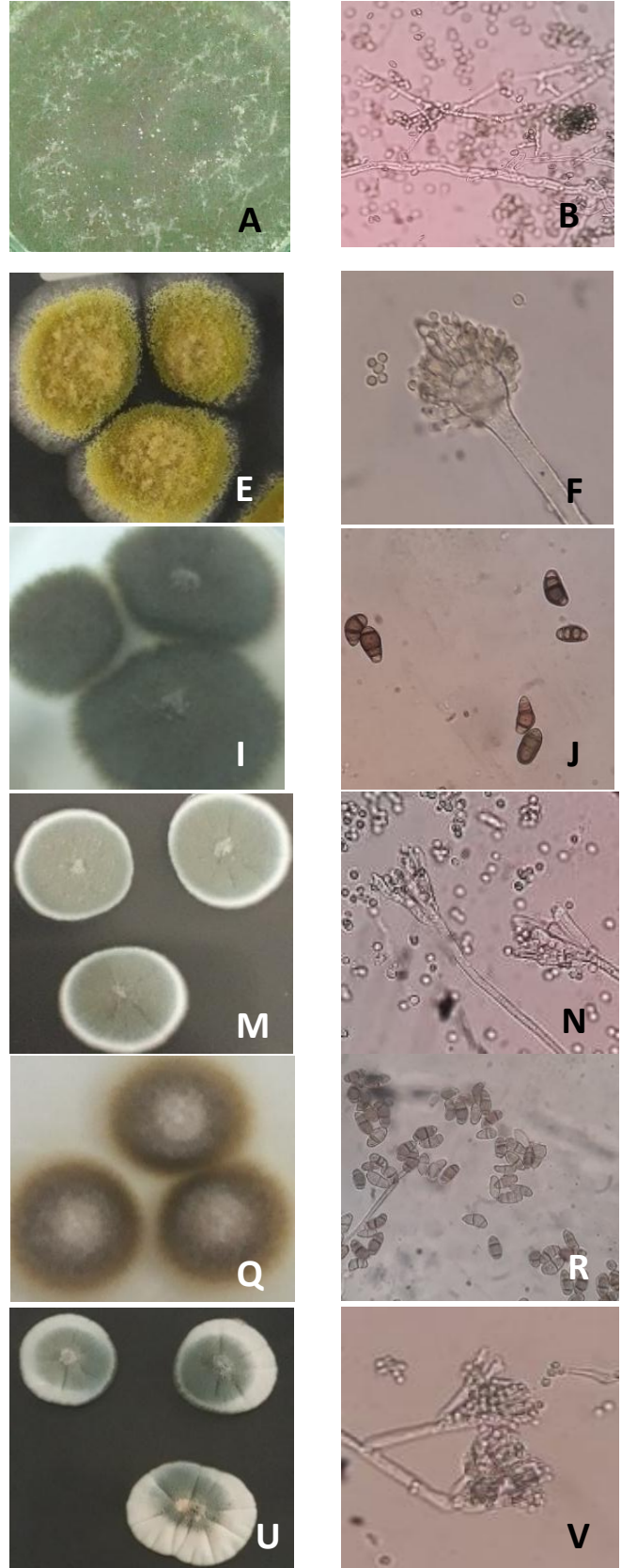

Gambar 1. Makroskopis dan mikroskopis isolat PFM11 (A \&B); PFM12 (C \& D); PFM111 (E \& F); PFM21 (G \& H); PFM27 (I \& J); PFM31 (K \& L); PFM33 (M \& N); PFM39 (O \& P); PFM3A (Q \& R); EFM4D (S \& T); EFM5B (U \& V); PFM116 (W \& X).

Kapang filoplan dan endofit tersebut berpotensi di bidang agrikultur, industri, medis, dan sebagainya. Hal ini dibuktikan oleh penelitian Khaerati (2018) yang menguji beberapa kapang filoplan dan endofit dari karet yang diujikan
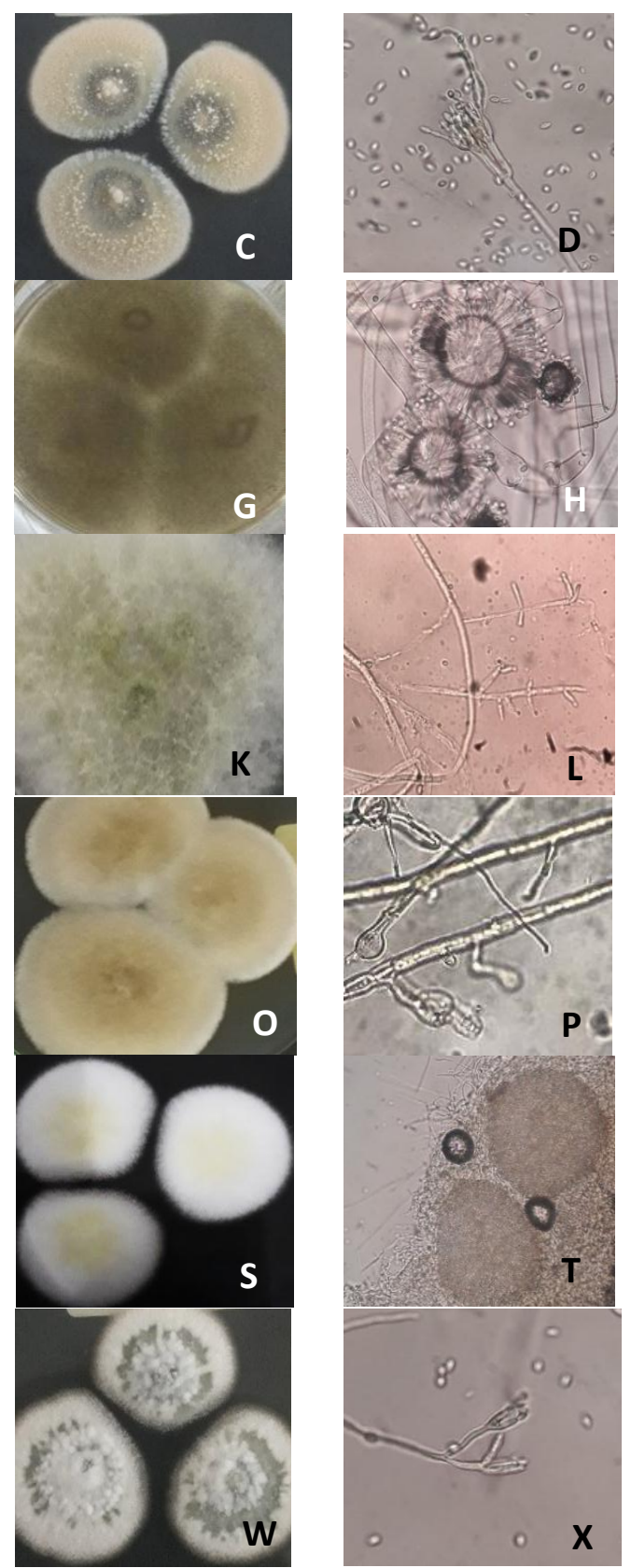

0

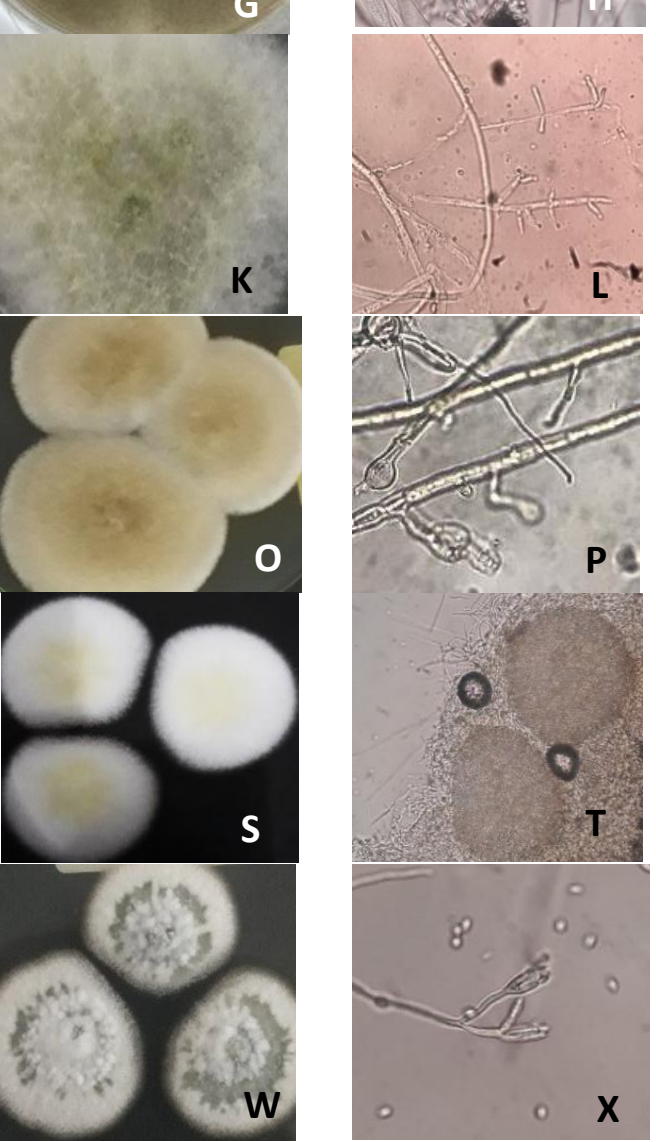

$\mathbf{S}$
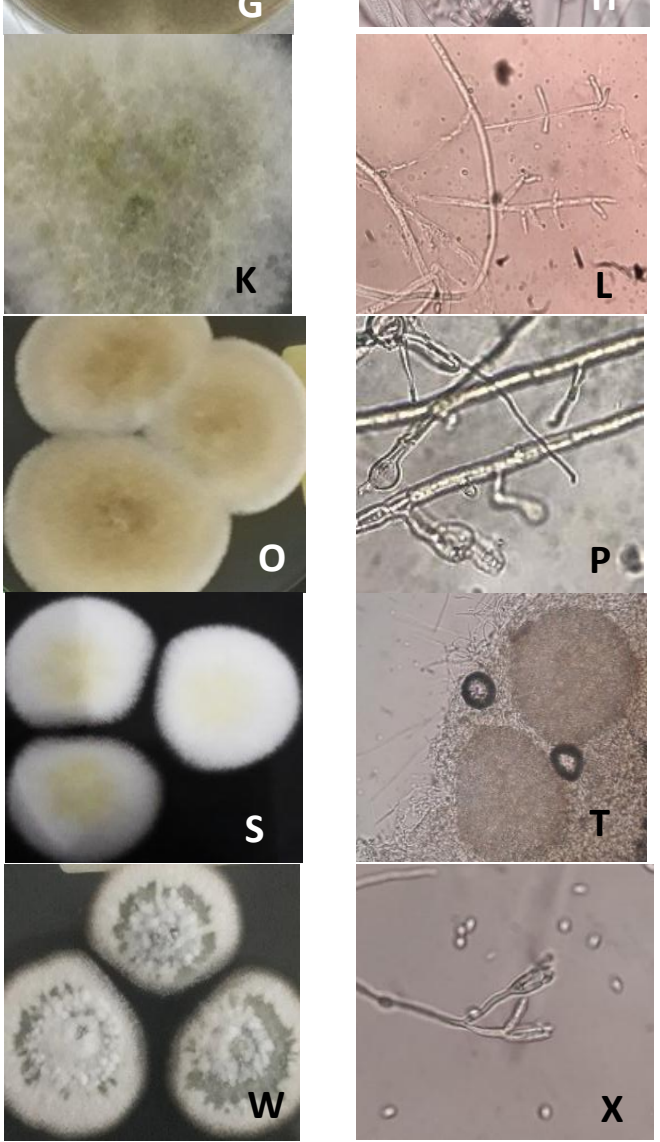

$x$ 
membuktikan bahwa beberapa kapang filoplan yang didapatkan seperti Aspergillus, Syncephalastrum, dan Trichoderma memiliki kemampuan yang baik dalam menghambat kapang C. gloeosporioides. Thakur dan Harsh (2016) juga menemukan bahwa $T$. harzianum yang diisolasi dari permukaan daun mampu menghambat kapang fitopatogen Alternaria alternata penyebab penyakit bitnik pada $R$. serpentina. Selain itu, potensi kapang endofit mampu memproduksi enzim, anti-herbivor, antagonis terhadap mikroba penyakit, dan lain sebagainya (Selim et al., 2012). Beberapa penelitian sebelumnya membuktikan bahwa kapang simbion baik filoplan maupun endofit sangat berpotensi di berbagai bidang. Kapang tersebut perlu diuji lanjut bagaimana kemampuannya dalam menghasilkan senyawa bioaktif dan lain sebagainya.

\section{Kesimpulan}

Berdasarkan penelitian karakterisasi kapang filoplan dan endofit dari tanaman A. marina yang telah dilakukan, diperoleh delapan genus kapang, diantaranya Aspergillus, Penicillium, Trichoderma, Syncephalastrum, Paecilomyces, Talaromyces, Curvularia, dan satu isolat yang belum diketahui genusnya.

\section{Ucapan Terima Kasih}

Penulis mengucapkan terima kasih kepada bapak Indra dan bapak Eko atas segala bantuannya selama penelitian di laboratorium bioteknologi Universitas Diponegoro

\section{Referensi}

Aroca, Ricardo (2013). Symbiotic Endophytes. Springer: Verlag Berlin Heidelberg.

Atlas, M. Ronald. (2010). Microbiological Media 4th Edition. CRC Press, New York.

Chauhan, Deepika, Swami, Abhishek \& Navneet (2014). Studies on Phylloplane Microflora of Dhak (Butea monosperma (Lamk.) Taub). Journal of Emerging Technologies and Innovative Research. (1): 638-643. https://www.jetir.org/papers/JETIR1407010 . $\mathrm{pdf}$
Elkhateeb, Waill, \& Daba, Ghoson (2018). Where to Find? A Report for Some Terrestrial Fungal Isolates, and Selected Applications Using Fungal Secondary Metabolites. Journal of Scientific Research. 4 (4). DOI: 10.26717/BJSTR.2018.4.001070

Evueh, G.A. \& Ogbebpr, N. O. (2008). Use of phylloplane fungi as biocontrol agent against Colletotrichum leaf disease of rubber (Hevea brasiliensis Muell. Arg.) African Journal of Biotechnology, 7 (15), pp. 2569-2572. DOI: 10.5897/AJB07.757

Khaerati, Ferry, \& Y., Rusli. (2018). Selection of Phylloplane and Endophyte Microbes as Biocontrol for Rubber Leaf Fall Disease (Corynespora cassiicola). Jurnal Tanaman Industri dan Penyegar. 5: 113. 10.21082/jtidp.v5n3.2018.p113-122.

Klich, M.A. (2002). Identification of Common Aspergillus Species. Centraalbureau Voor Schimmelcultures: Netherlands.

Lunggani, A.T., \& Suprihadi, A. (2018). Characterization phosphate-solubilizing marine actinobacteria associated with Sargassum sp from Menjangan kecil island, Indonesia. Journal of Physics ISNPINSA. Conf. Ser. 1217

Mahardhika, W.A., Rukmi, M.I., \& Pujiyanto, S. (2021). Isolasi Kapang Endofit dari Tanaman Ciplukan (Physalis angulata L.) dan Potensi Antibakteri terhadap Escherichia coli dan Staphylococcus aureus. NICHE Journal of Tropical Biology, 4 (1): 33-39 (doi:10.14710/niche.4.1.33-39).

Robertson, Alongi (1992). Avicennia marina. http://www.iucnredlist.org. Diakses pada 16 April 2021

Shaukat, S.S., Zafar, H., Khan, A., Ahmed, W., \& Khan, M.A. (2014) Diversity of Phylloplane Mycobiota of Two Mangrove Species Ceriops tagal and Aegiceras corniculatum Under Natural and Greenhouse Condition. International Journal of Biology and 
Biotechnology. 11 (2-3): 299-307. ISSN: 1810-2719

Samsons, R.A., \& Hoekstra, E.S. (2004). Introduction to Food and Airborne Fungi. Centraalbureau Voor Schimmelcultures: Netherlands.

Selim, Khaled, El-Beih, Ahmed, Abdel-Rahman, Tahany \& El Diwany, Ahmed. (2012). Biology of Endophytic Fungi. CREAM. 2: 31-82. 10.5943/cream/2/1/3.

Sopialena, Sopian \& Allita, L.D. (2019). Diversitas Jamur Endofit pada Tanaman Padi (Oryza sativa L.) dan Potensinya Sebagai Pengendali Hama. Jurnal Agroteknologi Tropikal Lembab. 2 (1). http://ejournals.unmul.ac.id/index.php/agro/article/ view/2462/pdf

Thakur, S. \& Harsh, N.S.K. (2016). Biocontrol Potential of Phylloplane Fungi Against Alternaria alternata Causing Leaf Spot in Rauwolfia serpentina in Vitro. International Journal of Scientific Research. 5 (2). https://www.doi.org/10.36106/ijss

Trianto, A., Radjasa, O.K., Purnaweni, H., Syaifudien, B.M., Djamaluddin, R., Tjoa, A., Singleton, I., Diele, K. \& Evan, D.
(2021). Potential of Fungi Isolated from A Mangrove Ecocystem in Northern Sulawesi, Indonesia: Protease, Cellulase, and Antimicrobial Capabilities. Biodiversitas Journal of Biological Diversity. 22. 17171724.

https://doi.org/10.13057/biodiv/d220415

Watanabe, T. (2010). Pictorial Atlas of Seed and Soil Fungi. CRC Press: USA.

Wijaya, T.A., Djauhari, S., \& Cholil, A. (2014). Keanekaragaman Jamur Filoplan Tanaman Kangkung Darat (Ipomoea reptans Poir.) Pada Lahan Pertanian Organik Dan Konvensional. Jurnal HPT. 2 (1). ISSN: $2338-4336$

Yan, Lu, Zhu, Jing, Zhao, Xixi, Shi, Junling, Jiang, Chunmei \& Shao, Dongyan (2019). Beneficial Effects of Endophytic Fungi Colonization on Plants. Applied Microbiology and Biotechnology https://doi.org/10.1007/s00253-019-09713$\underline{2}$

Yulia, E. \& Widiantini, F. (2007). Potensi Bakteri Antagonis Filoplen Daun Mangga dalam Menekan Penyakit Antraknosa Buah Mangga (Mangifera indica L.). Jurnal Agrikultura.18 (1). 